\title{
The technology of combined processing of extruded materials
}

\author{
Oleg Kirillov ${ }^{1}$, Vladislav Smolentsev ${ }^{1}$, and Sergey Yukhnevich ${ }^{1, *}$ \\ ${ }^{1}$ Voronezh State Technical University, Moskovsky Prospekt, 14, Voronezh, 394026, Russian \\ Federation
}

\begin{abstract}
The paper considers the peculiarities of combined processing of parts, made from extruded metal blanks with anisotropic electrotechnical properties. It involves the application of an electric field and seeks to achieve the required profile accuracy in any processing direction with precision within the specified tolerance for finishing operations. The study describes the specific nature of the development of current leads and the ways of achieving the required accuracy when combining electro-erosion and electrochemical components of the process in real time, taking account of the position of the pressing force vector relative to the direction of current flow in the zone of combined processing. This gives the opportunity to ensure the process stability and accuracy of processing advanced materials with a wide range of current conductivity variation in components, used when extruding blanks for precision parts. The study employs the methodology of calculating and assigning technological modes of combined processing, formed on the basis of the energetic approach and using the principle of similarity in technological systems. It also involves the adapted process management which allowed for elimination of unstable impacts affecting the accuracy of shape formation and surface layer quality, and expands the area of using combined processing for manufacturing extruded parts with anisotropic properties of components. The article presents the feasibility study of the ways of extending the work results to various types of products, particularly, to processing of welded and soldered joints of metallic materials and coated details where the replacement of traditional processing methods with combined ones significantly increases the opportunities for obtaining high-precision parts with required performance characteristics.
\end{abstract}

\section{Introduction}

In engineering, there is a great number of parts made of powder and granules having different machinability, which requires the creation of new ways of combined processing $[1 ; 2]$. In their planning, the modes of blank production must be considered as mode

\footnotetext{
* Corresponding author: serge1975@yandex.ru
} 
parameters, the main of which are pressure and direction of extrusion, as well as electrotechnical characteristics of components [3; 4], which can be ignored in traditional methods of mechanical processing [5]. This approach extends the scope of using the created combined methods to efficient processing of semiconductor products, as well as bimetals in soldered and welded structures, and also in splitting metal-coated parts. This can serve as a basis for creating a new scientific area within the technology of combined processing methods, and will stimulate the increase in the number of orders and the improvement of the commercially available and manufactured equipment for combined processing [6] of perspective engineering products.

\section{The peculiarities of combined processing of extruded materials}

Extruded materials are used for the manufacture of metal-cutting tools and in parts of the main production of modern aerospace engineering structures, due to which good results are achieved with respect to strength and specific mass of parts. Such materials can have evenly distributed particles or granules, as well as several composite layers, made from different homogeneous conductive layers, the processing of which by combined methods depends upon their physical and chemical characteristics, particularly, upon the specific resistance of a material. [4]. In conditions of producing new equipment, electrical methods of material processing are becoming the most demanded in engineering technology, which needs the scientifically grounded combination of several physical impacts with new (and often, unknown) mode parameters within a single combined process. This applies more to newly developed technological processes, which, along with sufficiently studied mechanical components, employ electrical, chemical, radial, magnetic and other impacts $[7 ; 8]$, taking account of the possibilities of achieving high technological parameters of processing new materials [9], particularly, those obtained by extrusion.

The study of the combined erosion-chemical process of machining extruded materials is underpinned by the principle of similarity, formulated for mechanical engineering [10]. It assumes that every physical impact within a single process not only retains its beneficial effect on all structural components of the blank material, but can also enhance such impact of other factors, for example, chemical processes in the processing zone. This can produce hardly explicable new technological results when processing various materials, such as sharp rise (by an order of magnitude or more) in processing speed and the declining of roughness with intensification of the removal process. This contradicts the classical provisions on assigning modes of roughing and finishing mechanical processing. There is practically no data on the variation in electrical resistance of extruded materials and its impact on their workability by combined methods [4].

\section{The ways of power supply in processing extruded parts}

For this purpose, it is necessary to justify the position and locations of current supply to the part, since it can have large thickness and a limited area of the bottom end section, most suitably matching the current lead. Any complication in the system of current leads results in increased labour costs when installing and removing a part from the machine tool, therefore, we consider three options for positioning current leads, namely: 1) on the machine table with current supply through the end face of a part;2) with the use of both end faces; 3 ) by installing extra current leads to the outer surface of the part. The different spacings from the site of current supply to the site of processing the material having high electrical resistance, which increases in the direction, perpendicular to the vector of 
extrusion, cause wide variation and loss of voltage. With improper positioning of current leads, it causes the disruption of the technological process and violation of technological parameters, mainly, the roughness of the surface layer, which is shown in figure 1.

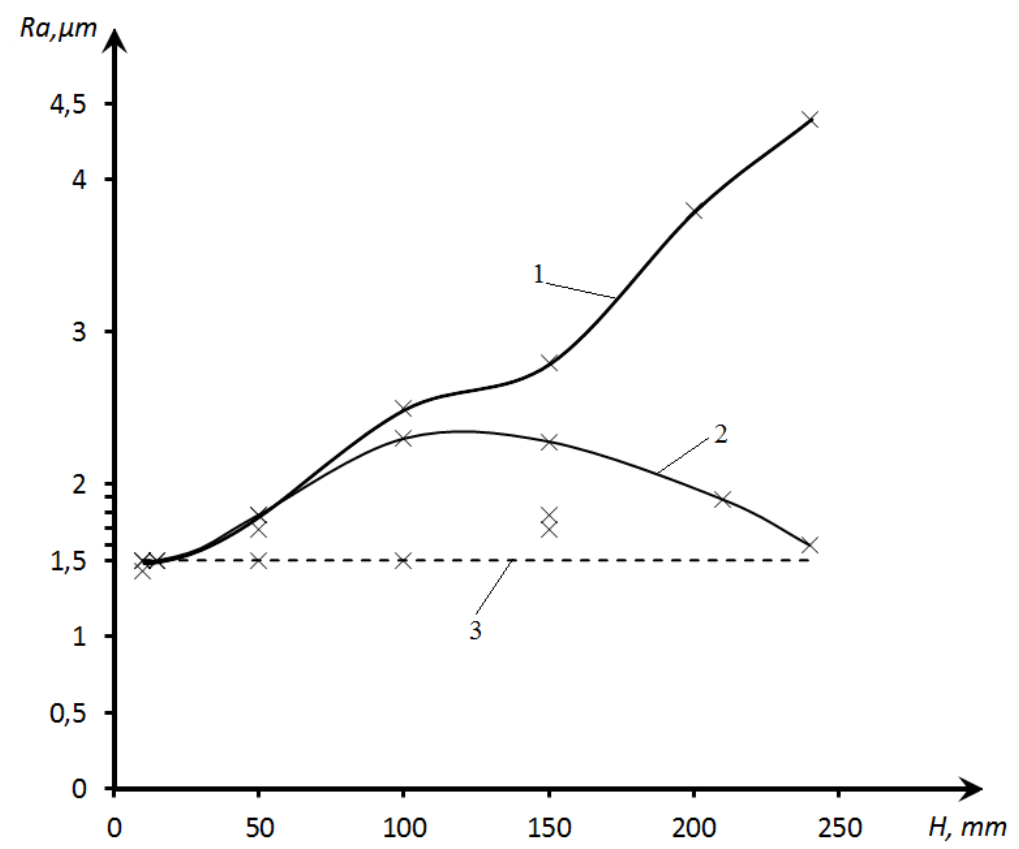

Fig. 1. The change in surface roughness of the combined processing site of an electrode-wire component, depending on the distance to the place of current supply (the pulse voltage is $280 \mathrm{~V}$ ). The conveyance of current to the part: 1 - from the side of the electrode wire exiting a part; 2 - from the opposite sides; 3 - from all sides.

The analysis of the fig. 1 shows that, with the unilateral current supply, involving the distancing of the processing zone from the site of the current lead, the height of irregularities increases up to 3 times and reaches the values, exceeding the one specified in the drawing. In other words, the unilateral current supply can be used for finishing of extruded mineral-ceramic and graphitized parts with a thickness of 30-50 mm. With the bilateral current supply, the roughness of $\mathrm{R}_{\mathrm{a}}<2 \mu \mathrm{m}$ can be obtained at a distance of not more than $70-75 \mathrm{~mm}$, that is, for parts with a thickness of up to $140-150 \mathrm{~mm}$. The limitations on thickness of parts are reduced during finishing in case 3 (fig.1), however, this is only true for products with a limited thickness of the side wall.

\section{The capabilities of the combined process for ensuring the processing accuracy of precision parts}

The fig. 2 presents the results achieved to ensure the accuracy of processing, meeting the requirements for precision parts.

It shows the most commonly used types of extruded materials during their combined processing, where there is a significant scattering of accuracy parameters. The tolerance change, depending on the divergence between the vectors of tool feeding and material extrusion, shows (fig.2), that the scattering of results (the scattering range is presented in fig.2) is basically within the limits of measurement accuracy. Therefore [11], while 
planning technological procedures of combined processing, we can assume the average tolerance value, which depends upon the depth of a hole (fig. 2a) for the most applicable piercing operation. In experiments, it is chosen to obtain a hole with a diameter of $3,2 \mathrm{~mm}$, involving the use of both solid and tubular shaped tool electrodes. With a larger tool section, the tubular shaped electrode is used more often, and the process flows according to the trepanning scheme. However, the experience shows that the results, presented in fig.2, provide the required accuracy of part processing. For precision holes and cavities, it is recommended to limit the depth of processing to $10-15 \mathrm{~mm}$. If greater depth is required, the subsequent calibration of the processed surface must be considered.
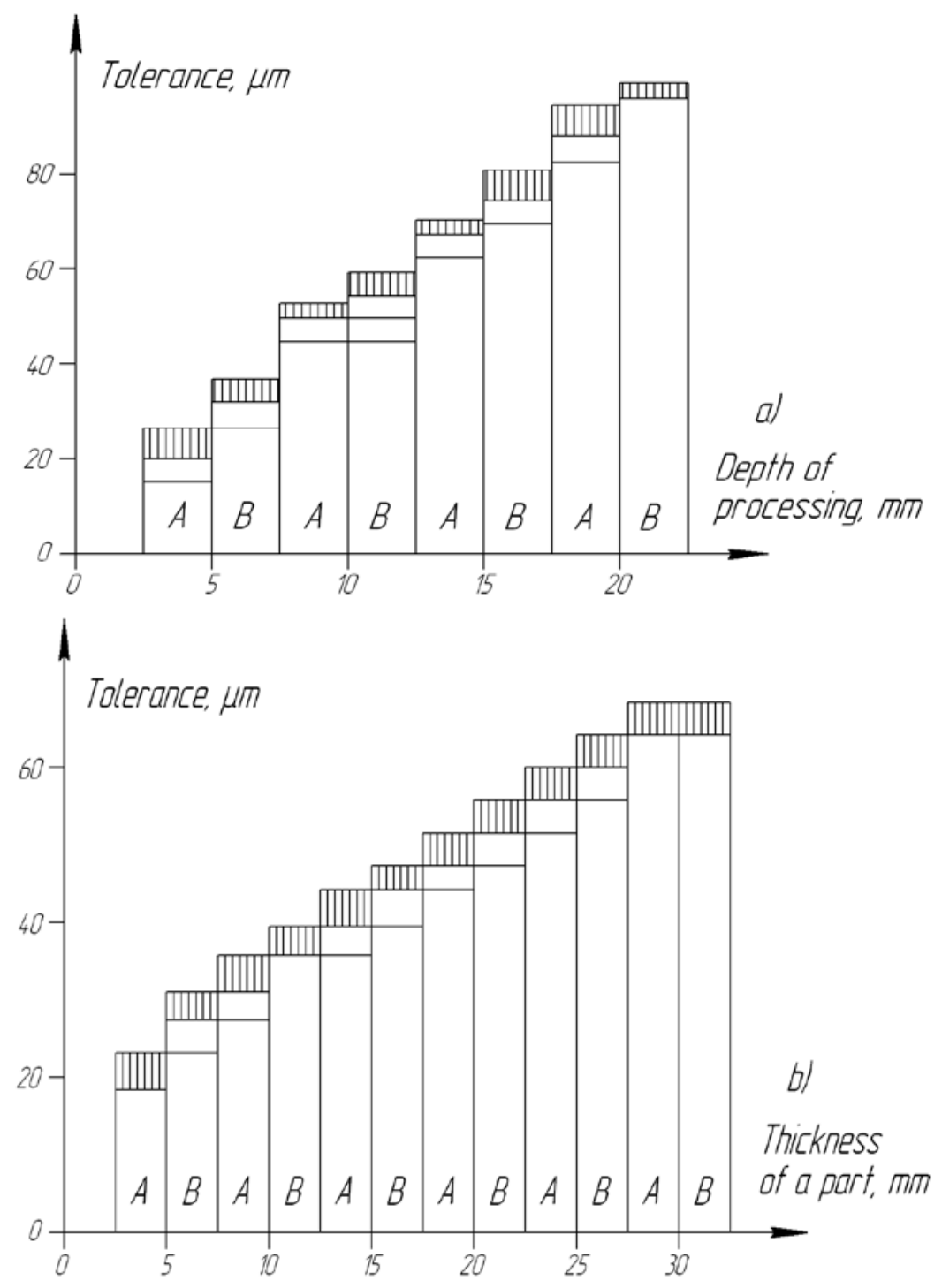

Fig. 2. The tolerance of combined processing of extruded materials (the aggregate parameters of all materials):

A - streamline and pressing force vectors coincide;

$\mathrm{B}$ - streamlines are perpendicular to the pressing force vector;

a - piercing of holes by a shaped electrode;

$\mathrm{b}$ - splitting by a non-profiled electrode 
The fig. $2 \mathrm{~b}$ demonstrates the studies on accuracy of splitting materials by a wire tool, presenting the limit tolerance values for multi-parameter processing. The brands of materials, solidity and the position of an electrode relative to the part were subject to variation. The lower value of electrode voltage was selected, ensuring the stable process flow. For precision parts made from all types of extruded materials, the accuracy of processing can be achieved up to the groove length of about $35 \mathrm{~mm}$.

\section{The peculiarities of planning technological modes of processing extruded parts by a wire electrode}

The technological processing modes depend not only on physical properties of powder particles or granules of incoming materials, but also on the geometry, the conditions of part extrusion, the choice of current feeding schemes, the process parameters and other factors.

With reference to combined processing of extruded parts [6] by a non-profiled wire electrode, the recommendations on the choice of technological modes are presented in the table.

Table 1. The modes of combined processing of extruded materials by a wire electrode (WE).

\begin{tabular}{|c|c|c|c|c|c|}
\hline $\begin{array}{c}\text { Materials processed } \\
\text { (specimen) }\end{array}$ & $\begin{array}{c}\text { Electrode } \\
\text { voltage, V } \\
\text { (not lower } \\
\text { than) }\end{array}$ & $\begin{array}{c}\text { Current, } \\
\mathrm{A}\end{array}$ & $\begin{array}{c}\text { Wire } \\
\text { electrode } \\
\text { tension, N }\end{array}$ & $\begin{array}{c}\text { Speed of } \\
\text { electrode } \\
\text { wire } \\
\text { rewinding, } \\
\text { m/min }\end{array}$ & $\begin{array}{c}\text { Recommended } \\
\text { speed of wire } \\
\text { electrode feed, } \\
\mathrm{m} / \mathrm{min}\end{array}$ \\
\hline $\begin{array}{c}\text { Metallic powders, } \\
\text { granules } \\
\text { (Cr17Ni13Mo2Ti) }\end{array}$ & 50 & $0,1-0,3$ & $20-25$ & $2-6$ & $0,7-2,5$ \\
\hline $\begin{array}{c}\text { Mineral ceramics } \\
\text { (WOC, composites) }\end{array}$ & $120-150$ & $0,2-0,4$ & $25-30$ & $3-15$ & $0,4-1,7$ \\
\hline $\begin{array}{c}\text { Iron-graphite (Iron, } \\
\text { graphite 3, } \\
\text { zinc sulphide 4) }\end{array}$ & $150-180$ & $0,2-0,4$ & $25-30$ & $3-15$ & $0,4-1,5$ \\
\hline
\end{tabular}

The data, presented in the table, reflects the processing of those types of extruded materials only, which have found wide application in mechanical engineering. In other cases, the adjustment of the modes is required, however, the information provided presents fairly reliable data on operating ranges of parameter variation, which significantly intensifies the planning of technological procedures for processing extruded materials. The conducted research has shown that the data, presented in the table, are valid both for powder and granular materials.

\section{Conclusion}

The combined processing involving the application of an electric field creates broader opportunities for technologists in the manufacture of parts from extruded metal blanks with anisotropic electrotechnical characteristics. The described process ensures the achievement of the required profile accuracy in any processing direction, with precision within the specified tolerance for finishing operations. The paper also presents the applicable options for supplying technical current, providing the achievement of the required accuracy with combination of electro-erosion and electrochemical process components, taking account of the position of the pressing force vector relative to the direction of current flow. 


\section{References}

1. O.N. Kirillov, The technology of combined processing by a non-profiled electrode. Voronezh State Technical University, P. 254 (2010)

2. E.V. Smolentsev, The planning of electrical and combined methods of processing. (Moscow: Mashinostroenie, 2005)

3. V. Gritsyuk, Processing of bimetals with superposition of an electrical field. SLV GSJ. Medunarodno svjetovanje International conference, Croatia, PP.81-87 (2004)

4. V.G. Gritsyuk, The workability of bimetallic products by anodic dissolution, Scientific work in university complexes: the collection of scientific papers. Moscow: Mashinostroenie, PP. 183-193 (2005)

5. The handbook of a mechanical engineer, edit. by A.M.Dalsky, A.G.Suslov et al. $5^{\text {th }}$ edition. Moscow: Mashinostroenie, Volume 2, P. 944 (2001)

6. V.P. Smolentsev, S.S. Yukhnevich, V.L. Mozgalin, The combined processing of extruded materials /, The Bulletin of Voronezh State Technical University. Volume 13, № 2, PP. 128-131 (2017)

7. V.P. Smolentsev, A.I.Boldyrev, G.P.Smolentsev, The technology of electro-erosion and electrochemical processing, Voronezh State University, P. 180 (2005)

8. Science-based technologies in mechanical engineering, Edit. by A.G.Suslov. (Moscow: Mashinostroenie, 2012)

9. V.F. Bezyazychnyi, V.Y. Zamyatin, A.Y. Zamyatin, Y.P. Zamyatin, The fundamentals of providing the quality of metal products with inorganic coatings,. (Moscow: Mashinostroenie, 2005)

10. S.V. Safonov, The technological provision of product performance parameters. (Voronezh: The publishing and printing centre of the VSU, 2015)

11. S.N. Grigoriev, E.V. Smolentsev, M.A. Volosova, The technology of processing by concentrated energy flows, Stary Oskol. The Publishing House «Tonkie Naukoemkie Tekhnologii», 2011) 